\title{
Freehand pedicle screw fixation: A safe recipe for dorsal, lumbar and sacral spine
}

\author{
Muhammad Junaid ${ }^{1}$, Ali Afzal'2, \\ Anisa Kalsoom ${ }^{3}$, Syed Sarmad Bukhari ${ }^{4}$
}

\begin{abstract}
Objective: To determine outcome of freehand pedicle screw fixation for dorsal, lumbar and sacral fractures at a tertiary care centre in the developing world.

Methods: A retrospective review was performed of 150 consecutive patients who underwent pedicle screw fixation from January 1, 2012 to $31^{\text {st }}$ December 2017. A total of 751 pedicle screws were placed. Incidence and extent of cortical breach by misplaced pedicle screw was determined by review of intra-operative and post-operative radiographs and/or computed tomography.

Results: Among the total 751 free hand placed pedicle screws, four screws $(0.53 \%)$ were repositioned due to a misdirected trajectory towards the disc space. six screws $(0.79 \%)$ were identified to have cause moderate breach while four screws $(0.53 \%)$ cause severe breach. There was no occurrence of iatrogenic nerve root damage or violation of the spinal canal.

Conclusion: Free hand pedicle screw placement based on external landmarks showed remarkable safety and accuracy in our center. The authors conclude that assiduous adherence to technique and preoperative planning is vital to success.
\end{abstract}

KEYWORDS: Freehand technique, Pedicle screw fixation, Spinal fracture.

How to cite this:

doi: https://doi.org/10.12669/pjms.35.3.981

Junaid M, Afzal A, Kalsoom A, Bukhari SS. Freehand pedicle screw fixation: A safe recipe for dorsal, lumbar and sacral spine. Pak J Med Sci. 2019;35(3):680-684. doi: https://doi.org/10.12669/pjms.35.3.981

This is an Open Access article distributed under the terms of the Creative Commons Attribution License (http://creativecommons.org/licenses/by/3.0), which permits unrestricted use, distribution, and reproduction in any medium, provided the original work is properly cited.

1. Dr. Muhammad Junaid, FCPS IFAANS, Department of Neurosurgery, PNS Shifa Hospital,

Karachi, Pakistan.

2. Dr. Ali Afzal, FCPS,

Department of Neurosurgery,

Jinnah Postgraduate Medical Center,

Karachi, Pakistan.

3. Dr. Anisa Kalsoom, FCPS,

Department of Radiology,

Fauji Foundation Hospital,

Rawalpindi, Pakistan.

4. Dr. Syed Sarmad Bukhari, MBBS,

Department of Neurological Surgery,

Aga Khan University Hospital,

Karachi, Pakistan.

Correspondence:

Dr. Syed Sarmad Bukhari,

Department of Neurological Surgery,

Aga Khan University Hospital,

Karachi, Pakistan.

Email: sarmad.bukhari@aku.edu

* Received for Publication:

* Revision Received:

* Revision Accepted:

\section{INTRODUCTION}

Pedicle screw fixation with rod constructs has attained global acceptance for stable spine fixation. ${ }^{1}$ A variety of techniques have been described in modern literature with free hand techniques having the unique advantage of being universally applicable, especially in the developing world with a dearth of equipment. ${ }^{2}$ These free-hand techniques rely heavily on a surgeon's experience and ability to locate the pedicle entry point with anatomical landmarks. Freehand pedicle screw placement in the lumbar spine has enjoyed wide acceptance but screw placement in the thoracic spine is more challenging due to the critical regional neurovascular anatomy and the narrow pedicular corridor mandating higher accuracy and precision. ${ }^{3}$

The modern surgeon has excellent aides to enhance accuracy and safety of placement of pedicle screws in the spine which include intraoperative C-arm 
fluoroscopy, intraoperative computer tomography (CT), and computer-assisted navigation. ${ }^{4}$ Although these adjunct technologies have gained popularity, limitations include radiation exposure to the patient and surgeon as well as added high cost and prolonged operative times. ${ }^{5}$ Keeping in view the hazards of intraoperative radiation, the ability to place pedicle screws with anatomic landmarks alone are paramount.

Freehand pedicle screw placement in the thoracic spine is considered both safe and effective and routinely performed by many spine surgeons. ${ }^{6}$ However based on each surgeon' straining and individual preferences there is no one single or uniform technique and considerable variations exist among studies that may not provide easily reproducible parameters. In addition, depending on the thoracic spinal level or region, many techniques have described varying entry points and trajectories. ${ }^{7}$ The study describes our step-by-step technique, which relies on a uniform entry point and sagittal trajectory for all levels.

\section{METHODS}

The study was conducted at the department of Neurosurgery at PNS Shifa Hospital in Karachi, Pakistan after obtaining approval from the Institutional Review Board. The duration of study was five years from $1^{\text {st }}$ January 2012 to $31^{\text {st }}$ December 2017 with a follow up of six months to one year. A retrospective review was performed of 150 consecutive patients who underwent pedicle screw fixation. A total of 751 pedicle screws were placed. This included patients of either sex, aged between 15 to 70 years. After taking history

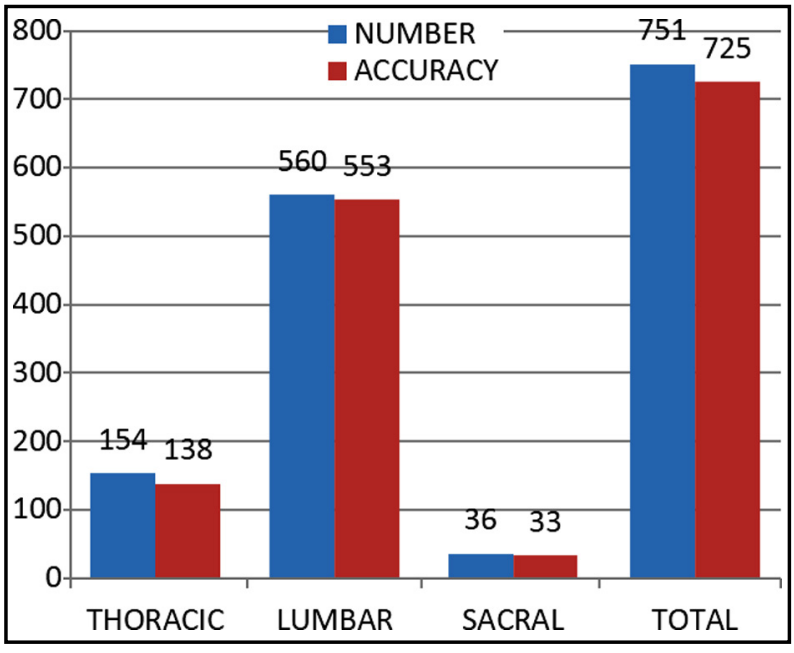

Graph.1: Screw accuracy per spinal level. and doing clinical examination, a preoperative radiological assessment was done by using $X$ rays anterio-Posterior and lateral views, MRI and CT scan with 3-D reconstruction of the lumbosacral spine. Patients above the age of 70 years, nontraumatic fractures, with associated disc herniation, previously operated and those who underwent fixation involving fluoroscopic guidance were excluded.

All the screws were inserted with free-hand technique using anatomic landmarks as a guide for an entry site. We used the following entry points: thoracic spine; $3 \mathrm{~mm}$ caudal to the junction of the transverse process and the lateral margin of the superior articulating process, and the sagittal trajectory was always orthogonal to the dorsal curvature of the spine at that level as described by Fennel et al, in lumbar spine; the junction of the pars interarticularis, the midpoint of the transverse process and the inferior point of the superior articular facet, in sacral; the infero-lateral margin of the basis of the superior articular process of the sacrum

We collected data on the number of patients, the number of inserted pedicle screws, and parameters of the surgical technique (entry point, axial, and sagittal trajectories). Incidence and extent of cortical breach by misplaced pedicle screw was determined by review of intra-operative and post-operative radiographs and/or computed tomography.

Statistical Analysis: Data was analyzed by using Microsoft Excel. Percentages and frequencies were calculated.

\section{RESULTS}

There were $107(71.3 \%)$ males and 43 (28.7\%) females with a mean age of $34.84 \pm 14.6$ years.

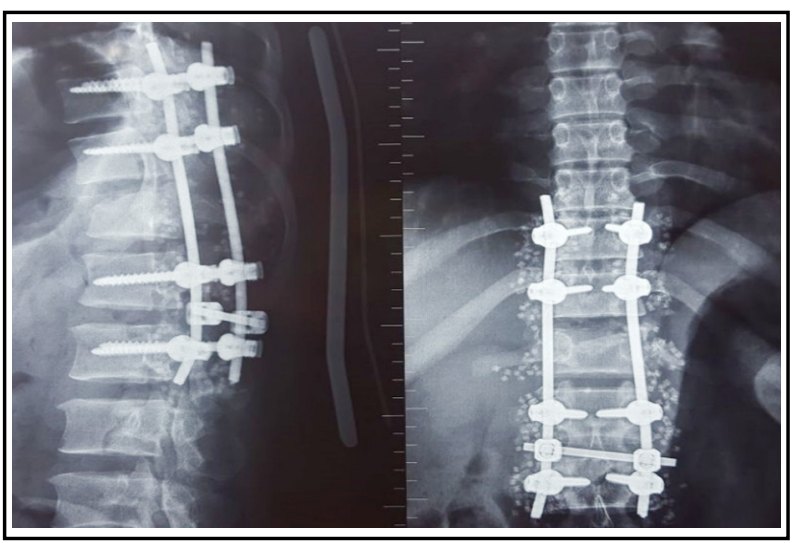

Fig.1: Plain X-ray thoracolumbar spine showing post-operative images of a D11-L3 fixation for a L1 compression fracture. 
Freehand pedicle screw fixation

Table-I: Screw characteristics.

\begin{tabular}{|c|c|c|c|c|c|c|c|}
\hline \multirow[t]{3}{*}{ Spinal level } & \multirow[t]{3}{*}{ Number } & \multirow[t]{3}{*}{ Accuracy } & \multicolumn{4}{|c|}{ Breaches $n=20$} & \multirow[t]{3}{*}{ Misdirected $n=6$} \\
\hline & & & \multirow{2}{*}{ Major $n=8(1.06 \%)$} & \multicolumn{3}{|c|}{ Minor $n=12(1.59 \%)$} & \\
\hline & & & & Medial & Lateral & Inferior & \\
\hline Thoracic & 154 & $89.6 \%$ & 5 & 0 & 6 & 2 & 3 \\
\hline Lumbar & 560 & $98.7 \%$ & 3 & 0 & 2 & 0 & 2 \\
\hline Sacral & 36 & $91.7 \%$ & 0 & 0 & 1 & 1 & 1 \\
\hline Total & 751 & $96.5 \%$ & 8 & 0 & 9 & 3 & 6 \\
\hline
\end{tabular}

The lumbar spine was the commonest site of placement with 561(74.6\%) screws, followed by thoracic in $154(21.4 \%)$ and sacral in 36(4\%). Among the total 751 free hand placed pedicle screws,12 screws $(1.59 \%)$ were identified to have cause minor breach out of which nine had lateral breaches and 3 inferior breaches (Table-I). Minor breaches didn't require repositioning and were only identified by postoperative imaging. There were no medial breaches while 8 screws $(1.06 \%)$ caused major breach/misdirected and were identified peroperatively due to giving way feel of screws which were rectified there and then. $6(0.79 \%)$ screws had partially misdirected trajectory towards the disc space and were left undisturbed due to good individual holding strength and of the whole construct. No repositioning was done postoperatively. The overall accuracy of screw placement was $96.5 \%$ (Fig.1).There was no occurrence of iatrogenic nerve root damage or violation of the spinal canal or any vascular complication or CSF leak

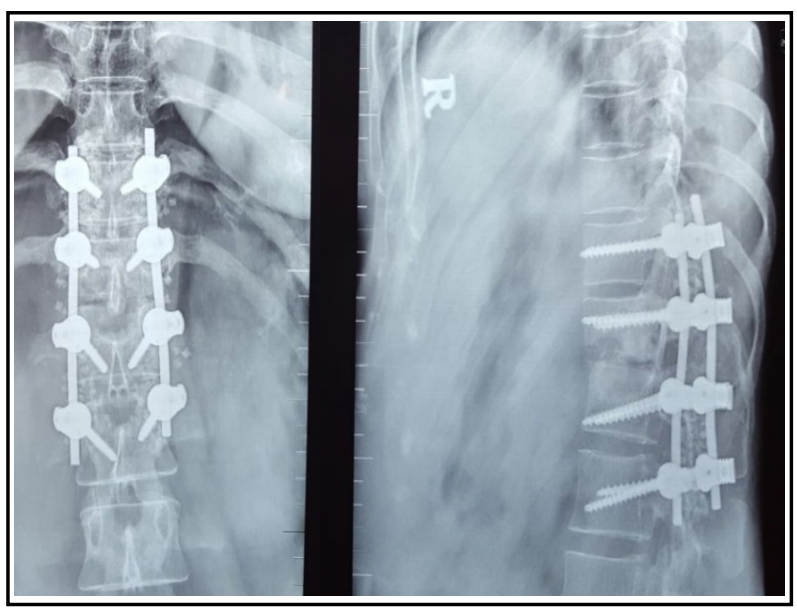

Fig.2: Plain X-ray thoracolumbar spine showing post-operative images of a D11-L2 fixation for a D12-L1 collapse.

\section{DISCUSSION}

The placement of freehand pedicle screws especially in the dorsal spinal segment can be a challenge due to the varied and complex anatomy of the thoracic vertebrae, with a potential for screw malposition and neurovascular injury. 2,6,8,9 Even though the modern spinal surgeon has various intraoperative navigational tools in his arsenal, sustained radiation exposure over one's career is concerning. To avoid harmful effects of radiation, freehand pedicle screw placement is becoming the preferred modality of fixation for a diverse number of pathologies ranging from trauma to tumors. ${ }^{10}$ Command over freehand techniques based on basic anatomy is not only essential for budding surgeons but valuable in settings where availability of neuronavigation is limited.

The mean accuracy for placement of the screws in our patient group was $96.6 \%$.Literature search reveals that over 8,000 screws have been placed in different studies with the mean accuracy for

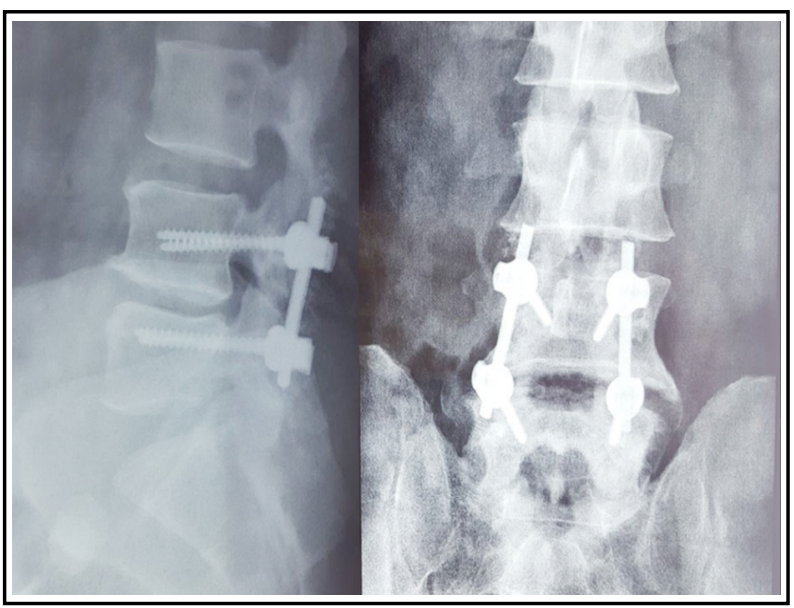

Fig.3: Plain X-ray thoracolumbar spine showing post-operative images of a L4-5 pedical screw fixation for dynamic listhesis. 
placement of the thoracic screws at $93.3 \%$ where the pedicle screw accuracy was defined as "having the entire screw contained within the cortices of each respective pedicle" ${ }^{11}$ The overall mean accuracy rate for pedicle screws placement in studies was $93.34 \%$ (standard deviation of 3.54). The lowest reported accuracy was $87.4 \%^{12}$ in screws only at $\mathrm{T} 1$ and the highest was $98.3 \%$ in their series of 964 patients. $^{13}$ Modi et al. calculated the difference inaccuracy for spine pathologies and found that the accuracy for patients with adolescent idiopathic scoliosis was $86.1 \%$, patients with cerebral palsy $-91.7 \%$, Duchenne's muscular dystrophy - 95.9\%, spinal muscular atrophy $-90.2 \%$, and polio $-84.4 \%$. The differences between diseases were not statistically significantly. ${ }^{14}$ In studies with multiple surgeons; the accuracy for five surgeons was $93.8 \%{ }^{15}$ and for eight surgeons was $98.3 \% .^{16}$

Among the total 751 free hand placed pedicle screws, 12 screws $(1.59 \%)$ were identified to have cause minor breach out of which 9 had lateral breaches and three inferior breaches. Minor breaches didn't require repositioning and were only identified by postoperative imaging. In a study with a total of 720 screws inserted, 623 screws $(86.5 \%)$ were perfect and 97 screws $(13.5 \%)$ were misplaced. ${ }^{17}$ Among these, 39 screws (40.2\%) were medial and $58(59.8 \%)$ were lateral, which shows that the prevalence of lateral misplacement was more in comparison to medial misplacement with reported deviation of the screw $<2 \mathrm{~mm}$ (Grade 1) and no misplacement in the inferior and superior.

Most studies agree on the defined "safe zone" ranging from 2 to $4 \mathrm{~mm}$ for pedicle screw breach of the vertebral bodies. This safe zone allows the medial or lateral wall breach by the screw without clinical consequences for the patient. ${ }^{18,19} \mathrm{Kim}$ YW et al. defined a breach of $<2 \mathrm{~mm}$ as a "definite safe zone", a breach of 2 to $4 \mathrm{~mm}$ a "probable safe zone", and a breach of 4 to $8 \mathrm{~mm}$ as a "questionable safe zone" ${ }^{20}$ In a study by Karapinar L et al., the majority of the breaches were labelled as minor $(<2 \mathrm{~mm})$ in the thoracic spine..$^{21}$ Overall, a lateral breach was more common than a medial breach of the vertebral bodies. There was a range of $2.5 \%$ to $21.6 \%$ of the screws for lateral breach and $1.7 \%$ to $13.2 \%$ of the screws for medial breach, with the majority falling below $5 \%$ of the screws. ${ }^{22,23}$

Increasing number of centres are now shifting towards robotic surgery and several studies comparing freehand conventional techniques for pedicle screw fixation robot-assisted (RA) have been published, but with equivocal results. A meta- analysis of five studies with 257 patients and 1105 screws revealed that there was no difference in the accuracy between robot-assisted and conventional freehand pedicle screw placement at the $0 \mathrm{~mm}$ grading criteria (RR 1.08, $95 \%$ CI 0.86, 1.35), and at $2 \mathrm{~mm}$ grading criteria (RR 1.02, $95 \%$ CI 0.68, 1.51) ${ }^{24,25}$ Further high-quality studies are required to unequivocally recommend one surgical technique over the other.

There was no complication encountered in our series which is consistent with the majority of studies in literature which reported no neurological or vascular complications following freehand placement of thoracic screws. The study by Kim, YW et al. gives the strongest evidence of the safety of this technique with their series of 3,204 screws with the longest follow-up (10 years) without any neurological or vascular complication reported. ${ }^{19}$ Parker et al. ${ }^{4}$ compared eight different surgeons and found an overall low complication rate in the over 3,000 screws placed again suggesting that the technique is still safe when used by different surgeons. The overall complication rate after freehand pedicle screw placement in the thoracic spine was low with a $4.3 \%$ incidence of durotomies in their case series which included both thoracic and lumbar freehand screw placement. ${ }^{13}$

Lastly, while freehand thoracic screw placement techniques are universally employed, there is dearth of published studies outlining the technical nuances which is further complicated by various starting points and/or trajectories for each level of the thoracic spine, making the adoption of one technique awkward to the spinal surgeon or trainee.

\section{CONCLUSION}

Free hand pedicle screw placement based on external landmarks showed remarkable safety and accuracy in our centre. The authors conclude that experience and assiduous adherence to technique and preoperative planning is vital to success.

Grant Support \& Financial Disclosures: None.

\section{REFERENCES}

1. Avila MJ, Baaj AA. Freehand Thoracic Pedicle Screw Placement: Review of Existing Strategies and a Step-by-Step Guide Using Uniform Landmarks for All Levels. Cureus. 2016;8(2):e501.

2. Fennell VS, Palejwala S, Skoch J, Stidd DA, Baaj AA. Freehand thoracic pedicle screw technique using a uniform entry point and sagittal trajectory for all levels: preliminary clinical experience. J Neurosurg Spine. 2014;21:778-784. doi: 10.3171/2014.7.SPINE1489 
3. Kim YJ, Lenke LG, Bridwell KH, Cho YS, Riew KD. Free hand pedicle screw placement in the thoracic spine: is it safe? Spine (Phila Pa 1976). 2004;29:333-342. doi: 10.1097/01. BRS.0000109983.12113.9B

4. Parker SL, McGirt MJ, Farber SH, Amin AG, Rick AM, Suk I, et al. Accuracy of free-hand pedicle screws in the thoracic and lumbar spine: analysis of 6816 consecutive screws. Neurosurgery. 2011;68:170-178. doi: 10.1227/ NEU.0b013e3181fdfaf4

5. Rivkin MA, Okun JF, Yocom SS. Novel free-hand T1 pedicle screw method: Review of 44 consecutive cases. J Neurosci Rural Pract. 2014;5:349-354. doi: 10.4103/0976-3147.139974

6. McCormack BM, Benzel EC, Adams MS, Baldwin NG, Rupp FW, Maher DJ. Anatomy of the thoracic pedicle. Neurosurgery. 1995;37:303-308. doi: 10.1227/00006123 199508000-00016

7. Hartl R, Theodore N, Dickman CA, Sonntag VKH. Technique of thoracic pedicle screw fixation for trauma. Operative Tech Neurosurg. 2004;7(1):22-30. doi: 10.1053/j.otns.2004.04.005

8. Roy-Camille R, Saillant G, Berteaux D, Salgado V. Osteosynthesis of thoraco-lumbar spine fractures with metal plates screwed through the vertebral pedicles. Reconstr Surg Traumatol. 1976;15:2-16.

9. Kim YJ, Lenke LG. Thoracic pedicle screw placement: free-hand technique. Neurol India. 2005;53:512-519. doi: $10.4103 / 0028-3886.22622$

10. Motiei-Langroudi R, Sadeghian H. Assessment of pedicle screw placement accuracy in thoracolumbosacral spine using freehand technique aided by lateral fluoroscopy: results of postoperative computed tomography in 114 patients. Spine J. 2015;15:700-704. doi: 10.1016/j.spinee.2014.12.012

11. Gelalis ID, Paschos NK, Pakos EE, Politis AN, Arnaoutoglou $\mathrm{CM}$, Karageorgos AC, et al. Accuracy of pedicle screw placement: a systematic review of prospective in vivo studies comparing free hand, fluoroscopy guidance and navigation techniques. Eur Spine J. 2012;21:247-255. doi: 10.1007/s00586-011-2011-3

12. Carbone JJ, Tortolani PJ, Quartararo LG. Fluoroscopically assisted pedicle screw fixation for thoracic and thoracolumbar injuries: technique and short-term complications. Spine (Phila Pa 1976). 2003;28:91-97. doi: 10.1097/00007632200301010-00021

13. Cui G, Wang Y, Kao TH, Zhang Y, Liu Z, Liu B, et al. Application of intraoperative computed tomography with or without navigation system in surgical correction of spinal deformity: A preliminary result of 59 consecutive human cases. Spine (Phila Pa 1976). 2012;37:891-900. doi: 10.1097/ BRS.0b013e31823aff81

14. Modi H, Suh SW, Song HR, Yang JH. Accuracy of thoracic pedicle screw placement in scoliosis using the ideal pedicle entry point during the freehand technique. Int Orthop. 2009;33:469-475.

15. Weinstein JN, Spratt KF, Spengler D, Brick C, Reid S. Spinal pedicle fixation: reliability and validity of roentgenogrambased assessment and surgical factors on successful screw placement. Spine (Phila Pa 1976). 1988;13:1012-1018.
16. Zhang $\mathrm{C}$, Wang $\mathrm{Z}$, Zhang $\mathrm{C}$, Chen $\mathrm{F}$, Zhang $\mathrm{H}$, Yan $\mathrm{X}$. Spine Bull's-Eye Robot guidewire placement with pedicle standard axis view for thoracic and lumbar pedicle screw fixation. J Spinal Disord Tech. 2012;25:E191-E198. doi: 10.1097/BSD.0b013e31825ef937

17. Baaj AA, Beckman J, Smith DA. O-Arm-based image guidance in minimally invasive spine surgery: technical note. Clin Neurol Neurosurg. 2013;115:342-345. doi: 10.1016/j. clineuro.2012.05.007

18. Amiot LP, Lang $K$, Putzier M, Zippel H, Labelle $\mathrm{H}$. Comparative results between conventional and computerassisted pedicle screw installation in the thoracic, lumbar, and sacral spine. Spine (Phila Pa 1976). 2000;25:606-614. doi: 10.1097/00007632-200003010-00012

19. Assaker R, Reyns N, Vinchon M, Demondion X, Louis E. Transpedicular screw placement: image-guided versus lateral-view fluoroscopy: in vitro simulation. Spine (Phila $\mathrm{Pa}$ 1976). 2001;26:2160-2164. doi: 10.1097/00007632200110010-00024

20. Kim YW, Lenke LG, Kim YJ, Bridwell KH, Kim YB, Watanabe $\mathrm{K}$, et al. Free-hand pedicle screw placement during revision spinal surgery: analysis of 552 screws. Spine (Phila Pa 1976). 2008;33:1141-1148. doi: 10.1097/BRS.0b013e31816f28a1

21. Karapinar L, Erel N, Ozturk H, Altay T, Kaya A. Pedicle screw placement with a free hand technique in thoracolumbar spine: is it safe? J Spinal Disord Tech. 2008;21:63-67. doi: 10.1097/BSD.0b013e3181453dc6

22. Hyun SJ, Kim YJ, Cheh G, Yoon SH, Rhim SC. Free hand pedicle screw placement in the thoracic spine without any radiographic guidance: Technical note, a cadaveric study. J Korean Neurosurg Soc. 2012;51:66-70. doi: 10.3340/ jkns.2012.51.1.66

23. Laine T, Lund T, Ylikoski M, Lohikoski J, Schlenzka D. Accuracy of pedicle screw insertion with and without computer assistance: A randomised controlled clinical study in 100 consecutive patients. Eur Spine J. 2000;9:235240. doi: $10.1007 / \mathrm{s} 005860000146$

24. Liu $\mathrm{H}$, Chen $\mathrm{W}$, Wang $\mathrm{Z}$, Lin J, Meng B, Yang $\mathrm{H}$. Comparison of the accuracy between robot-assisted and conventional freehand pedicle screw placement: a systematic review and meta-analysis. Int J Comput Assist Radiol Surg. 2016;11(12):2273-2281.

25. Yu L, Chen X, Margalit A, Peng H, Qiu G, Qian W. Robotassisted vs freehand pedicle screw fixation in spine surgery - a systematic review and a meta-analysis of comparative studies. Int J Med Robot. 2018;14(3):e1892. doi: 10.1002/ rcs.1892.

\section{Author`s Contribution:}

MJ conceived and designed the study.

AA did data collection and manuscript writing.

AK did statistical analysis \& editing of manuscript.

SSB did review and final approval of manuscript. 